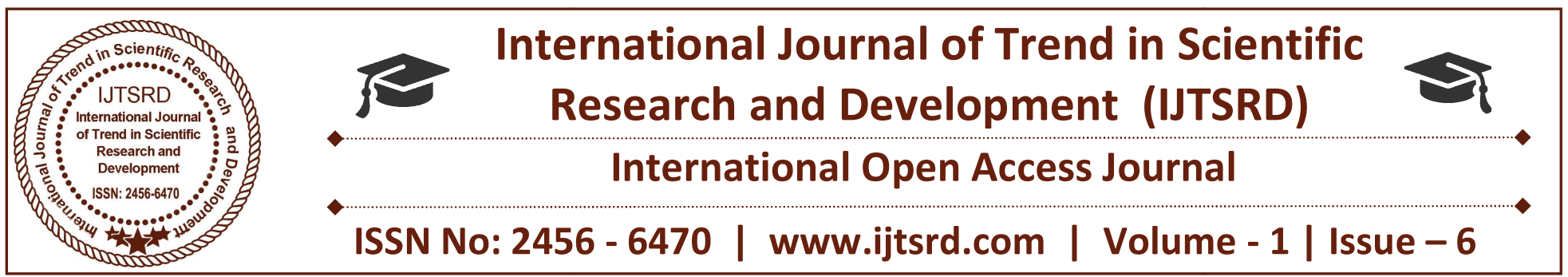

\title{
Perceived Benefits \& Effectiveness of Peer Teaching and Learning methods among Nursing Students at a Private University in Oman
}

\author{
Shanthi Ramasubramaniam \\ Online Instructor, Independent \\ Researcher, Ex-Faculty of College \\ of Health Sciences, University of \\ Buraimi
}

\author{
Grace Angeline \\ Clinical Instructor \\ College of Health Sciences, \\ University of Buraimi, \\ Buraimi, Sultanate of Oman
}

\author{
Blessy Anderson \\ Clinical Instructor \\ College of Health Sciences, \\ University of Buraimi \\ Buraimi, Sultanate of Oman
}

"Learning results from what the student does and thinks and only from what the student does and thinks. The teacher can advance learning only by influencing what the student does to learn."

- Hebert Simon

\section{ABSTRACT}

Use of Peer teaching and learning in nursing education encourages active learning and improves confidence among them. The objectives of this study were to assess the perceived benefits and to test the effectiveness and overall satisfaction of peer teaching learning methods introduced among nursing students studying at a private university in the Sultanate of Oman. A quasi experimental one group pre-test, posttest design was utilized for the study. A total of 97 students from the fifth and sixth semester of the nursing degree programme were included as participants in the study. The results of the study highlighted the benefits listed by the nursing students as motivation for self-learning, accountability to do self-learning, able to identify their problems in learning, seek help when needed, respect for costudents, increased observation techniques, and acquisition of knowledge about the topic learned. Majority of students were highly satisfied by this method of peer teaching and cooperative learning method and were satisfied overall with this new method. Utilizing this innovative method into different courses of the nursing programme would prove beneficial to students and encourage their involvement and accountability towards self-learning. Key words: Peer teaching and learning, Cooperative learning, innovative teaching and learning, perceived benefits of peer learning, overall satisfaction.

Note: The terms Peer teaching and cooperative teaching are synonymously used throughout this article.

\section{INTRODUCTION}

Self-directed and proactive learning can be enhanced by the use of new innovative teaching and learning methods in nursing education. The current trend in nursing education has shifted its focus more on innovative teaching techniques. Nursing education prepares the nursing students to be as a critical thinker, manager, educator, patient advocate and care giver. Many studies have documented that the use of innovative teaching methods, shows evidence of developing proactive learners. New innovative teaching strategies can enhance active learning process and improve the quality of nursing education. There are a variety of teaching techniques which can gain students attention. A few among those are peer teaching and learning, simulation in learning, cooperative teaching and learning, problem based learning, case studies, online course learning, teaching 
through games and role play, concept mapping, jigsaw classroom and debating (Jie-hui-Xie 2016). The mission statement of directorate general of education and training in the Sultanate of Oman insists to introduce the innovative teaching methods into the nursing curriculum (DGET 2010). Hence a study to assess the student's perception and experience of the newly introduced teaching technique was carried out in a private university of Sultanate of Oman. The university (where this study was conducted) insists to include peer teaching and learning as one of the method to improve teaching and learning among the students. The educators at the university believed that introducing peer teaching and innovative methods will increase the involvement of students and to make them understand selfresponsibility for their learning process.

The term peer teaching and learning is known by different interchangeable titles like "cooperative learning, mentoring, peer review coaching, team learning," and it has been widely used in the undergraduate nursing education. It enhances critical thinking, psychomotor skills, cognitive development, and academic gains (Goldsmith.L.et.al, 2006). A systematic review by Robyn Stone.et.al, 2013 stated that Peer learning is characterized by students learning from each other and form independently sourced information. In this method of learning, the student is centered in the small group and the case is discussed and analyzed with the content as a meaning of learning. As mentioned by Allan H. T et.al, 2008 and Shipman. \& Hooten J 2008 who cited from Stone Robyn.et al 2013, that in nursing a huge number of nursing students are in pressure and the use of innovative teaching methods of learning would be beneficial. Hughes et al, 2003 did a study to investigate effect of an informal peer group experience on baccalaureate nursing students recommended that there is a need for longitudinal study on nursing at varying stages in course. Lin et al, 2010 compared the educational results of peer tutor problem-based learning and conventional teaching in nursing ethics education. The study reported the outcome as both methods effective for teaching ethics with PBL $(<0.01)$ slightly more effective than conventional lecture $(=0.020)$.

Secomb2008 communicated through her study that peer teaching and learning is an effective educational intervention for nursing students during their clinical placements. The study further reported preclinical strategies are required before clinical placements for students with poor academic performance. A study from Egypt carried out by El-Sayed, Metwally and Abdeen2013, on effect of peer teaching among undergraduate nursing students enrolled in nursing administration course and indicated that there was an increase in their performance score. The authors further reported that students who adopted this peer teaching method agreed upon the benefits obtained as peer teacher and as students. Similarly the pediatric cardio-pulmonary resuscitation skills acquired by nursing students using this peer teaching and learning method was found to be a better performed skill when compared to traditional method of teaching (Sabaq A.G, Farouk M and Ismail S.S, 2016). All the above studies provide evidence for the effectiveness of teaching strategy in various nursing courses including clinical learning, nursing administration, nursing ethics and skills acquisition. Not all studies were compared the peer teaching with the traditional method of teaching, as most of the studies used a quasi-experimental approach. Evaluating the effectiveness of the peer teaching and learning also varied among the studies which were reviewed as support for the current study.

\section{The Objectives of the Study were the following.}

1. Determine the perceived benefits and acceptance of the cooperative teaching and learning strategy including overall satisfaction of nursing students with this innovative method.

2. Evaluate the effectiveness of cooperative teaching method among the selected undergraduate nursing courses.

\section{METHODOLOGY:}

The study was done at a private University in Oman. The University offers European study programs. It also has various streams of colleges including Health sciences, engineering and Business studies. The innovative method was introduced in the nursing degree program at the college of health sciences. A Quasi experimental, one group post-test design was the research approach used. Students registered for 3 different courses of the nursing program were experimented with the cooperative teaching strategy in selected topics. The effectiveness was tested with the quiz grades obtained before and after the methodology was introduced. The perceived benefits and overall satisfaction of nursing students who were 
inducted with the innovative and cooperative teaching and learning methods was assessed through a five point likert scale. The courses which introduced this peer teaching and cooperative learning wereCourse1Health care in special situations-II - topic -Arthritis, total hip replacement (musculoskeletal disorders) osteoporosis and care of stump.

Course- 2 Selected illnesses including diagnostic therapy II- topic-sexually transmitted diseases, uterine structural abnormalities (female reproductive system).

Course-3 Selected Illnesses including Diagnostics \& Therapy III-topic-Neurotic Disorders

Sample Size: The sample size consisted of 97 nursing students consisting of 89 female students and 8 male students, who were from 3 different courses at the fifth and sixth semester level of the Bachelor of nursing program of spring 2015.

Ethical Considerations: The investigators obtained the ethical committee clearance and permission from the research committee, and from the Dean of College of health sciences. The study was explained to the study participants, and students who were willing to participate in this research were included. An individual consent was obtained from all respondents. The students were reassured that the participation was voluntary and they would withdraw at any point of time and would not reflect in their grades.

Development of the Tool: A five point likert scale with 5 items and 5 options to assess the level of satisfaction and the level of acceptance was developed after extensive literature review and expert opinion. The study materials were developed by the subject teachers and were given to 3 other experts in the same specialization to get the content validity. The accuracy of the developed, five point likert scale was assessed by using Cronbach's alpha method. The estimated 'r'values for the perceived benefits was 0.72 and for the overall satisfaction scale it was 0.75 .

\section{Context and Interventions of the Study:}

After the informed consent and brief description about the study, a pretest was administered to the participants. The students were given the study materials which were prepared by investigators (faculty 1,2 and 3) specific to the selected courses and topics to be delivered using the innovative teaching methods. Then the students were divided with partners (pairs) and also in groups of 6 each. The students read the material, understood and asked the instructor if they needed any help and resources. They shared information first with partners, next with small group and then finally with the whole class. The total time duration was 2 hours from the allotted time of the specific course. The study was planned in the 4th week of spring 2015. A quiz was conducted at the end of the cooperative teaching and learning method and was compared with the quiz scores without the use of the innovative teaching technology. A five point likert scale was given at the end to assess the acceptance and overall satisfaction of this new peer teaching and learning method. The students were asked to list down the benefits of the peer teaching and learning methods.

\section{DATA ANALYSIS:}

Data entry and statistical analysis were done using SPSS 16.0 Statistical software package. The study utilized the data of pre and post test marks and the individual responses on the level of satisfaction,OS1Overall Satisfaction (Acceptance of peer assisted / cooperative teaching and learning) OS2- Overall Satisfaction (Satisfaction of the innovative teaching and learning method) PB- Overall perceived benefits of the teaching and learning method.

The percentage distribution, $Z$ tests, Pearson's correlation coefficient tests, Kruskal-Wallis, ONE WAY ANOVA tests were used to interpret the data.

\section{NOTE: abbreviations in data:}

OS1- Overall satisfaction (Acceptance of peer assisted / cooperative teaching and learning)

OS2-- Overall satisfaction (Satisfaction of the innovative teaching and learning method)

PB- Overall perceived benefits of the teaching and learning method.

CP- Clinical practice (level of clinical practice starts from 2nd semester as CP1- until final year semester as CP7)

\section{Insert figure 1 and 2}

\section{Demographic data of participants:}

The percentage of participants involved in the peer teaching and learning process is $8.25 \%$ consisting of male students and $91.75 \%$ of female students. As nursing is a female dominated profession it is quite common to have more number of female participants. 
The levels of study of participants were as follows. $29.89 \%$ of the students were enrolled in CP3, 50.51\% in $\mathrm{CP} 4,4.12 \%$ in $\mathrm{CP} 5$ and $15.46 \%$ in $\mathrm{CP} 6$. Majority of students were from clinical practice 4 .

The number of participants from each course was, $39.17 \%$ of them were registered in the course "Health Care in Special Situations II", $28.86 \%$ of them were registered in the course "Selected Illnesses is including Diagnostics and Therapy III" and 31.95\% of them were registered in the course "Selected Illnesses includes Diagnostics and Therapy II.

The percentage of students with CGPA 3.7-4 was $18.55 \%$. The percentage of students with CGPA 3-3.6 was $43.29 \%$. The percentage of students with CGPA 2-3 was $38.15 \%$. (The CGPA-cumulative grade point average is the evaluative system followed in the university where the study was conducted).

Discussion: An innovative teaching method attracts student's attention and makes the learning more effective. The results are discussed based on the objectives of the study.

The first objective was to assess the perceived benefits, acceptance of students on the cooperative teaching and learning strategy including overall satisfaction of nursing students with this innovative method. This was evidenced by the benefits listed individually by the nursing students during and after the study. Majority of the students $86 \%$ said that it motivated them to do self-learning, the other benefits listed by the students were accountability to do selflearning $(62 \%)$, able to identify their problems in learning (34\%), seek help when needed, respect for co-students, increased their observation techniques, and acquisition of knowledge about the topic learned. These were the benefits listed by the individual nursing students as per their experience and opinion after participating in the study. The new teaching method was widely accepted by $36 \%$ of the nursing students who were highly satisfied by this method and $40 \%$ of them were moderately satisfied with this innovative teaching method. The peer teaching depends upon the ability of students, their confidence levels and sense of self responsibility among them. At this point, this shows that the students generally accepted this method of teaching. These findings are similar to the study done by Sabaq et al 2016, where the performance score of nursing students who learned by peer teaching was significantly better than those trained by assistant teaching staff in traditional clinical settings. Loke, A.J.T., Chow, F.L.W., 2007 reported in their study findings that students had both positive and negative experiences from peer tutoring, but they had a domination of positive experiences. The current study results are consistent with the findings of studies done by Sabaq et al 2016 Loke, A.J.T., Chow, F.L.W., 2007.

The second objective was to assess the effectiveness of cooperative teaching among the selected undergraduate nursing courses. This objective was tested with the change in the quiz or test scores. The below pretest posttest marks provides an understanding that after involving in peer teaching in selected nursing subjects the students had an improvement in their grades. For understanding purposes grade A above $80 \%$, grade B $65-80 \%$, grade C 50-65\%, grade D 30-50\% and grade Fbelow 30\% and means a failure in the specified course. It is evident from analysis that in the course "Health Care in Special Situations 2", majority of the participants $(63.15 \%)$ scored grade C. There is also a marked decrease in the percentage of students with $\mathrm{D}$ grade $(57.89 \%$ in the pretest to $7.89 \%$ in the post test).

It is evident that for the "course selected illnesses including diagnostics and therapy 3 " the percentage of students in grade D significantly reduced from $75 \%$ in the pretest to $21.42 \%$ in the post test and there is no student who received grade F.The analysis shows that the course "selected illnesses including diagnostics and therapy II" majority of the students (70.96\%) scored $\mathrm{A}+, 16.12 \%$ of them scored grade $\mathrm{A}$ and there is no student who received grade $F$. The Wilcoxon signed-ranks test using the $\mathrm{Z}$ statistic reveals that the Significance value is less than .05 showing that there is difference in median values of Pretest Percentage of Marks and posttest Percentage of Marks. Moreover Correlation tests indicated that there is statistically significant (at the 0.01 level -2 tailed) relationship between posttest percentage of marks and OS1and OS2, which shows that the peer/ innovative / cooperative teaching methods are satisfactory; however the extent of relationship was low. The results of the study did also have some students $(2 \%)$ who did not find the new method more beneficial and acceptable due to personal difficulties in understanding the course and the topic. Ultimately this study showed that the cooperative and peer teaching method in nursing education were perceived to be beneficial and widely accepted by students. The 
test scores also proved the effectiveness of the innovative teaching method. The new teaching and learning method can encourage the teacher himself or herself where it can bring about inevitable changes in nursing education. Use of more interactive methods of teaching and learning in nursing educationis the need of the hour for democratization of knowledge and to bring out the facilitator role of the nurse educators. The results of this study are consistent with those done by Yazici 2005, where the results showed that there was increase in grades when cooperative teaching strategy was used. Similarly a study done by L.Lakshmi 2014 also showed that the Partners' teaching was an effective innovative teaching method. There are a lot of studies done worldwide utilizing innovative teaching methods in curriculum but very few have done a comparative study between the traditional method (lecture) and the new innovative teaching and learning methods like peer and cooperative learning.

Kruskal- Wallis H-test ONE WAY ANOVA showed that there was a statistically significant difference in OS1, OS2, based on the individual course; however values of $\mathrm{PB}$ do not vary with the course content as significance value is greater than .05 , thus providing information that the overall satisfaction and acceptance of this new teaching methodology is high and that the perceived benefits do not vary with the content of course. It is to be noted that peer teaching involving same level or semester students in the process may have variations in teaching style, understanding concepts.

\section{Insert table 1 and 2}

\section{Researcher's observations during data collection:}

Three faculty dealing with 3 different courses mentioned above served as guide and facilitators during the peer and cooperative teaching and learning process. To give additional information regarding the involvement of students, the faculty documented their anecdotes and observations during each session. The anecdotes were summarized and are given below.

\section{Researcher's observation- Faculty 1}

Majority of the students showed interest to participate in the innovative teaching method. Students used mobile dictionaries to find out additional information and English vocabulary. Participants were eager to know their quiz scores and answers for the questions immediately after the post test.

\section{Researcher's observation- Faculty 2}

Most of the students were found to be actively involved in discussing, contributing, making summary points/ notes, taking initiative to find word meanings etc, It was also observed that distraction of students was very minimal. They were found to be more attentive in these sessions.

\section{Researcher's observation- Faculty 3}

Students in all groups were found to be encouraging their peers by explaining difficult concepts in their mother tongue in order to make them understand better. Some students volunteered to summarize the topic even though they were not the team leaders in the study group.

All these observations of faculty provide us valuable information regarding the involvement of students during the teaching learning process. Generally whenever a new innovative teaching method is introduced into the nursing courses, students may find it difficult to accept the changes. But the findings of the current study showcased the interest and involvement of students in accommodating the new method and the results also provide evidence for the same.

The students who were participants in the study also narrated their experience following the induction of this cooperative and peer teaching and learning method. A few examples of verbatim are given below. "I was scared at the beginning of the session and thought, will I be able to teach and learn from my friends. It was an interesting and challenging experience for me. It was possible with the guidance from instructors and the material they provided."CP3 student.

"I would rather prefer this method of teaching most useful as I could teach and learn the lessons in Arabic language"- CP4 student.

This student testimonial gives a clarity regarding their experience with the new teaching and learning method.

Implications and recommendations for future practice: Nursing students generally are under a lot of pressure and would invite new innovative strategies to achieve more benefits. The innovative methods could be introduced in more number of courses in each semester which promotes the quality of education. 
More research could be conducted to test the effectiveness of peer teaching or cooperative teaching in the clinical courses and practice also. A comparative study between traditional and new innovative methods among Arab nursing students using larger sample could provide more evidence in future. Implementing this peer teaching and cooperative teaching and learning to learn clinical skills will also enhance their performance skills.

\section{Limitations of the Study:}

The time duration for conducting or introducing the new teaching strategies was very less and it was critical for the instructors to complete it and as well as to complete the objectives of the course. Since the study was carried out in a single setting with small number of samples the study results cannot be generalized.

\section{CONCLUSION}

This research adds to the literature on use of peer teaching and cooperative teaching methods into different courses of the undergraduate nursing program. On the whole the study results proved that the peer teaching and the cooperative method of teaching and learning were well accepted by the nursing students and the satisfaction of students were also found to be high. The overall benefits proved the effectiveness of this new innovative teaching and learning method. The students also wish to continue to have innovative teaching methods introduced into to various courses.
Figure -1 OS1-Acceptance of peer teaching methodoverall

Acceptance of peer teaching as a innovative teaching and learning method

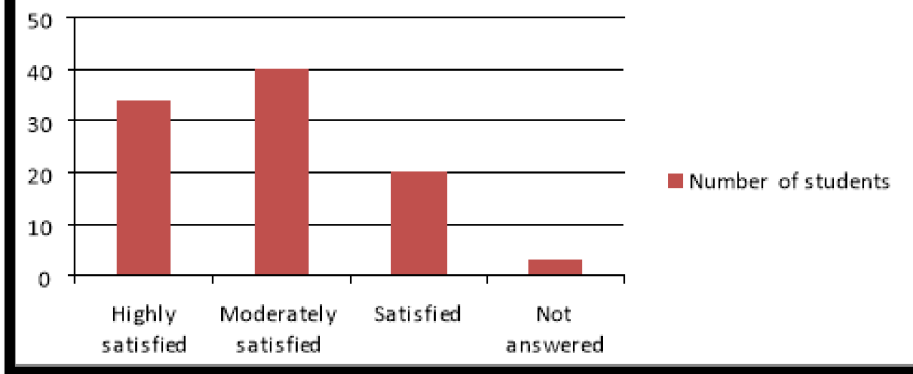

Figure 2-OS2- level of satisfaction of innovative teaching and learning among students

\section{Level of satisfaction of innovative teaching teaching and learning among students}

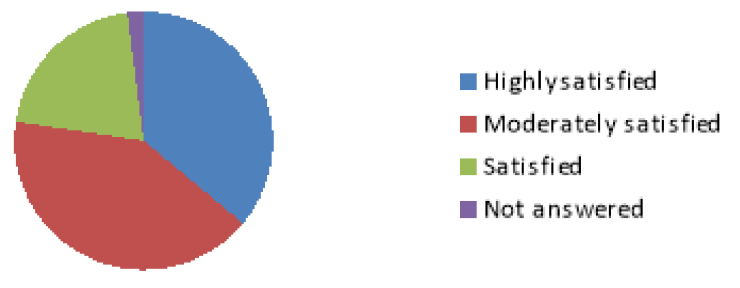

\begin{tabular}{|l|l|l|l|l|l|}
\hline \multicolumn{7}{|c|}{ Table 1- Descriptive Statistics } \\
\hline & N & Mean & Std. Deviation & Minimum & Maximum \\
\hline Marks & 97 & 37.6730488 & 15.75929615 & .00000 & 78.57143 \\
\hline posttest Percentage of & 97 & 69.9705447 & 21.45631124 & 10.00000 & 100.00000 \\
Marks & & & & & \\
\hline
\end{tabular}


Table 2- Correlation of Posttest marks with OS1 and OS2

\begin{tabular}{|c|c|c|c|c|c|}
\hline & & $\begin{array}{c}\text { Posttest Percentage } \\
\text { of Marks }\end{array}$ & PB & OS1 & OS2 \\
\hline \multirow{3}{*}{$\begin{array}{l}\text { Posttest } \\
\text { percentage } \\
\text { of marks }\end{array}$} & Pearson correlation & 1 & & & \\
\hline & Sig. (2- tailed & & & & \\
\hline & $\mathrm{N}$ & 97 & & & \\
\hline \multirow[t]{3}{*}{ PB } & Pearson correlation & -0.060 & 1 & & \\
\hline & Sig. (2- tailed) & .559 & & & \\
\hline & $\mathrm{N}$ & 97 & 97 & & \\
\hline \multirow[t]{3}{*}{ OS1 } & Pearson correlation & .417 & .167 & 1 & \\
\hline & Sig. (2- tailed) & .000 & .102 & & \\
\hline & $\mathrm{N}$ & 97 & 97 & 97 & \\
\hline \multirow[t]{3}{*}{ OS2 } & Pearson correlation & .344 & .151 & .753 & 1 \\
\hline & Sig. (2- tailed)" & .001 & .141 & .000 & \\
\hline & $\mathrm{N}$ & 97 & 97 & 97 & 97 \\
\hline
\end{tabular}

***Correlation is significant at the rate 0.01 level (2- tailed).

\section{HIGHLIGHTS:}

Nursing students face academic burden and would invite innovative teaching methods.

$>$ Peer and cooperative teaching prove to be beneficial to nursing students.

$>$ It showed increase in academic grades and student satisfaction.

$>$ The overall student satisfaction of these methods was high.

\section{ACKNOWLEDGEMENT:}

The authors would like to thank Dr.J.F. Thomas, Dean College of Health sciences who guided us throughout the study. The study was also conducted based on the recommendations of the study done by L. Lakshmi, MOH, Nursing Institute Oman 2014. 
International Journal of Trend in Scientific Research and Development (IJTSRD) ISSN: 2456-6470

\section{REFERENCES}

1) Goldsmith M, Stewart L, Ferguson L. (2006). Peer learning partnership: An innovative strategy to enhance skill acquisition in nursing students .Journal of Nurse Education Today. 26 (2): 123130. Available from: http://www.ncbi.nlm.nih.gov/pubmed/.

2) PMid:16202483

http://dx.doi.org/10.1016/j.nedt.2005.08.001.

3) Directorate general of education and training, Ministry of health, Oman, Mission statement 2010.

4) El-Sayed H.S, Metwally F. G and Abdeen A .M. (2013). Effect of peer teaching on performance of undergraduate nursing students enrolled in nursing administration course. Journal of nursing education and practice. 3(9) 156-166.

5) Jie-hui-Xie (2016). Tool box for teaching strategies in nursing education. Chinese nursing research. 3(2) 54-57.

6) Hughes, L. C., Romick, P., Sandor, M. K., Phillips, C. A., Glaister, J., Levy, K., \& Rock, J. (2003). Evaluation of an informal peer group experience on baccalaureate nursing students' emotional well-being and professional socialization. Journal of Professional Nursing, 19(1), 38-48. DOI: 10.1053/jpnu.2003.9.

7) Robyn Stone, Simon Cooper, and Robyn Cant (2013). The Value of Peer Learning in Undergraduate Nursing Education: A Systematic Review. ISRN Nursing, Article ID 930901, 10 pages, 2013. doi:10.1155/2013/930901.
8) H. T. Allan, P. A. Smith, and M. Lorentzon (2008). Leadership for learning: a literature study of leadership for learning in clinical practice. Journal of Nursing Management, 16, :5, pp. 545555.

9) D. Shipman and J. Hooten (2008). Without enough nurse educators there will be a continual decline in RNs and the quality of nursing care: contending with the faculty shortage. Nurse Education Today, vol. 28.5, pp. 521-523.

10) C. F. Lin, M. S. Lu, C. C. Chung, and C. M. Yang (2010). A comparison of problem-based learning and conventional teaching in nursing ethics education. Nursing Ethics, 17( 3), pp. 373-382.

11) Hulya Julie Yazici, (2005) "A study of collaborative learning style and team learning performance", Education + Training. 47 (3), pp.216-229, doi: 10.1108/00400910510592257.

12) Loke, A.J.T., Chow, F.L.W., 2007. Learning partnership $\mathrm{e}$ the experience of peer tutoring among nursing students: a qualitative study.International Journal of Nursing Studies.44, $237 \mathrm{e} 244$.

13) Mrs. Lakshmi Renganathan1, Dr. Salem Al Touby2, Mrs.ShanthiRamasubramaniam3 (2014). Is "Partners" (Cooperative Teaching and Learning) Method an effective Innovative teaching method for Arab Nursing Students?IOSR Journal of Nursing and Health Science. PP 21-25.

14) Secomb, J. (2008). A systematic review of peer teaching and learning in clinical education.Journal of Clinical Nursing. 17: 703-716. doi: 10.1111/j.1365-2702.2007.01954.x 